\title{
Guarana as a source of bioactive compounds
}

\author{
Cintia Pereira Silva ${ }^{a^{*}}$, Rosana Aparecida Manólio Soares-Freitas ${ }^{\mathrm{a}}$, Geni Rodrigues Sampaio ${ }^{\mathrm{a}}$, \\ Adriano Costa de Camargo ${ }^{a, b^{*}}$ and Elizabeth Aparecida Ferraz Silva Torres ${ }^{a}$
}

aNutrition Department, School of Public Health, University of São Paulo - USP, São Paulo, Brazil

bDepartamento de Ciencias Vegetales, Facultad de Agronomía e Ingeniería Forestal, Pontificia Universidad Católica de Chile, Casilla $306-$ 22, Santiago, Chile

*Corresponding author: Cintia Pereira Silva and Adriano Costa de Camargo, Nutrition Department, School of Public Health, University of São Paulo - USP, São Paulo, Brazil. E-mail: cintiasil@usp.br, adrianoesalq@gmail.com

DOI: $10.31665 / J F B .2019 .6182$

Received: June 18, 2019; Revised received \& accepted: June 26, 2019

Citation: da Silva, C.P., Soares-Freitas, R.A.M., Sampaio, G.R, de Camargo, A.C, and Torres, E.A.F.S. (2019). Guarana as a source of bioactive compounds. J. Food Bioact. 6: 1-5.

\section{Abstract}

A high daily intake of fruits and vegetables is an important strategy to promote health. The mechanism explaining the health benefits of plant food materials is attributed, at least in part, to their high content of bioactive phenolics. Guarana (Paullinia cupana) is a typical product from Amazon biota and, mainly as a source of caffeine; its seeds are commonly used as stimulants. However, guarana seeds are also rich in catechin, epicatechin, procyanidin B1, and procyanidin B2. Guarana exhibits potential health benefits in cognitive function and prevention of cardiovascular disease. Furthermore, it is a promising source of antihyperglycemic and antibacterial compounds for prevention and/or management of type 2 diabetes and oral diseases. However, to confirm these benefits in humans, clinical trials are needed to provide evidence for these anecdotal observations.

Keywords: Caffeine; Phenolic compounds; Antioxidant properties; Anti-Inflammatory potential; Antimicrobial activity.

Non-communicable diseases (NCDs) are the major health challenges of the 21 st century. In 2016 , they were responsible for $71 \%$ (41 million) death around the globe. NCDs include cardiovascular diseases (17.9 million death), cancers (9 million death), chronic respiratory diseases (3.8 million death), and diabetes (1.6 million death) (WHO, 2018).

Unhealthy diet is a behavioral risk factor linked to the main NCDs. However, several studies have shown that a high daily intake of vegetables and fruits may be helpful in health promotion. The mechanisms explaining these health benefits are related to the action of bioactive molecules such as phenolic compounds (Boeing et al., 2012; Abbas et al., 2017; Karasawa and Mohan, 2018), mainly due to their antioxidant potential.

Guarana (Paullinia cupana) is a typical product from Amazon biota. As a source of caffeine, its seeds are commonly used as a stimulant. In food processing, guarana seed extract is the base flavor used in the manufacture of one of the most popular Brazilian carbonated drinks. Furthermore, it is also used in the energy drink industry. Besides that, guarana has been listed in the Brazilian
Pharmacopoeia (Agência Nacional de Vigilância Sanitária, 2017) and is also introduced in the U.S. Pharmacopeia, under monographs for guarana seed, its powder and dry extract. The Brazilian Food Supplement Law recently recognized that guarana presents bioactive substances, hence supporting its role as a functional food ingredient (Agência Nacional de Vigilância Sanitária, 2018).

Literature data show that guarana seeds are good sources of catechin, epicatechin, procyanidin B1, procyanidin B2 (Schimpl et al., 2013; Yonekura et al., 2016). Due to its bioactive compounds, guarana has attracted considerable interest as an ingredient for the development of functional foods and food supplements. However, the health benefits of bioactive compounds depend not only on the intake levels but also on their bioavailability (BAv). The bioavailability is involved with digestion, absorption, metabolism, distribution, transporting, excretion, and colonic fermentation. Therefore, these parameters have to be considered (de Camargo et al., 2018; Shahidi and Peng, 2018; Shahidi et al., 2019).

In vitro methods to simulate gastrointestinal digestion allow determination of the bioaccessibility (BAcs) of bioactive compounds 
and evaluate the effect of food processing and to anticipate their action under systemic conditions. In line with this, recent studies have suggested the use of gastrointestinal digestion in functional food design (Cilla et al., 2018; Santana and Macedo, 2018).

Yonekura et al. (2016) have shown BAcs and BAv of phenolic compounds of guarana seed in their in vivo study. Mendes et al. (2019) evaluated the effect of macronutrients (milk casein, potato starch and vegetable oil) on BAcs of guarana catechins in Caco-2 cells. The results demonstrated that the interaction with other food macronutrients did not affect the permeability values of all tested compounds.

Guarana consumption may induce changes in lipid metabolism. Krewer et al. (2011) evaluated the associations of metabolic disorders and anthropometric and biochemical biomarkers of lipid, glucose and oxidative metabolism and the habitual ingestion of guarana by an elderly population. The reduction of prevalence of various metabolic disorders (hypertension, obesity and metabolic syndrome) was associated with guarana ingestion, thus suggesting a potential protective effect of regular consumption of guarana ingestion against metabolic disorders.

Oxidation of low-density lipoprotein-cholesterol (LDL-c) is known as a biomarker related to the development of coronary heart disease (Amarowicz, 2016). To investigate how guarana consumption protects against metabolic disorders, Portella et al. (2013) carried out an in vivo study to better understand the potential effects of guarana on LDL-c oxidation. Healthy elderly subjects who habitually ingested guarana demonstrated lower LDL-c oxidation than that of the control group (reduction of $27 \%, p<0.0014$ ). Furthermore, guarana exhibited a high antioxidant activity in vitro, mainly at concentrations of 1 and $5 \mu \mathrm{g} / \mathrm{mL}$, as demonstrated by decreased values of conjugated dienes (CDs) and thiobarbituric acid reactive substances (TBARS), tryptophan destruction and high total peroxyl radical-trapping potential (TRAP) activity.

Many studies suggest the link between the intake of dietary antioxidants and the reduction/prevention of cardiovascular diseases (CVD) (Chiu et al., 2018). The impact of these antioxidants stems from their protection towards LDL-c oxidation, which is recognized by its role in the early atherogenic process (Vauzour et al., 2010; Billingsley and Carbone, 2018).

Yonekura et al. (2016) assessed the effects of guarana consumption on plasma catechins, erythrocyte antioxidant enzyme activity (superoxide dismutase, catalase, and glutathione peroxidase) and biomarkers of oxidative stress (ex vivo LDL-c oxidation, plasma total antioxidant status and oxygen radical absorbance capacity (ORAC) values, and lymphocyte single cell gel electrophoresis) in healthy overweight subjects. These authors showed that daily intake of guarana had both acute and cumulative effects on GPx (glutathione peroxidase) and catalase, which are phase II antioxidant enzymes that reduce peroxides to water molecules. However, the antioxidant status markers such as reducing ex vivo LDL-c oxidation and hydrogen peroxide-induced DNA damage in lymphocytes improved only transiently. The authors believe that the daily dose of guarana was probably not enough to keep the fasting plasma catechin concentration above a threshold level required to exert direct antioxidant effects.

The anti-hyperglycemic potential of guarana seed consumption has been pointed as another important health benefit. The aqueous extract of guarana seeds was able to inhibit $\alpha$-glucosidase and $\alpha$-amylase activities in vitro (Silva et al., 2018). Studies have shown that catechins exhibit $\alpha$-glucosidase and $\alpha$ - amylase inhibitory activities (Cires et al., 2017; Hanhineva et al., 2010; Kim et al., 2016). Therefore, to confirm this hypothesis, further studies with guarana are warranted.

Gut microbiome is involved in the etiology of obesity and obe- sity-related complications such as non-alcoholic fatty liver disease (NAFLD), insulin resistance and type 2 diabetes mellitus (T2DM). The main species of the colonic microbiota are the genera $\mathrm{Bac}$ teroides, Bifidobacterium, Ruminococcus, Eubacterium and Lactobacillus (Canfora et al., 2019). Silveira et al. (2018) evaluated the effects of guarana seed powder (GSP) on gut microbial composition in Wistar rats after 21 days of treatment. GSP altered gut microbiota in a negative way, loss in diversity, decreased Bacteroidetes and increased Cyanobacteria abundance, probably due to other metabolites than caffeine. The modulation of gut microbiota by polyphenols is not fully understood. Human intervention studies provide the best models for studying the effect of phenolic compounds on modulation of gut microbiota. However, human intervention studies hold inevitable practical and ethical limitations (Ozdal et al.,2016).

Several phenolic compounds (e.g. catechins and proanthocyanidins) have been recognized as potential antimicrobial agents with bacteriostatic or bactericidal actions (de Camargo et al., 2017; Ozdal et al., 2016). Majhenič et al. (2007) tested guarana seed extracts against three food-borne fungi: Aspergillus niger, Trichoderma viride and Penicillium cyclopium, and three pathogenic bacteria: Escherichia coli, Pseudomonas fluorescens and Bacillus cereus. The results suggested that seed extracts of guarana possess strong antimicrobial action. Besides that, in vitro assessment of the antibacterial potential of the guarana extracts against Streptococcus mutans showed that these could be used in the prevention of bacterial dental plaque (Yamaguti-Sasaki et al.,2007).

Numerous plant extracts such as guarana have shown the ability to prevent carcinogenesis by reducing tumor size or relieve cancerrelated symptoms. Fukumasu et al. (2008) evaluated the effects of guarana in an experimental metastasis model. Cultured B16/F10 melanoma cells $\left(5 \times 10^{5}\right.$ cells/animal $)$ were injected into the tail vein of mice on the 7 th day of guarana treatment $\left(2.0 \mathrm{mg} \cdot \mathrm{g}^{-1}\right.$ body weight, per gavage) and the animals were treated with guarana daily up to 14 days until euthanasia (total treatment time: 21 days). Guarana treatment decreased proliferation and increased apoptosis of tumor cells, consequently reducing the tumor burden area.

Hertz et al. (2015) evaluated the effects of guarana on breast cancer cell response to 7 chemotherapeutic agents currently used in the treatment of breast cancer. MCF-7 breast cancer cells were cultured under controlled conditions and exposed to 1,5 and 10 $\mu \mathrm{g} . \mathrm{mL}^{-1}$ guarana concentrations, with and without chemotherapeutics (gemcitabine, vinorelbine, methotrexate, 5-fluorouracil, paclitaxel, doxorubicin and cyclophosphamide). The main results demonstrated the antiproliferative effect of guarana at concentrations of 5 and $10 \mu \mathrm{g} \cdot \mathrm{mL}^{-1}$ and a significant effect on chemotherapeutic drug action.

Cadoná et al. (2017) investigated the in vitro antitumor effect of guarana by inhibiting the AKT/mTOR/S6K and MAPKs pathways. Colorectal and breast cancer cell lineages, HT-29 and MCF7 cells, respectively, were exposed to different guarana concentrations $\left(0.1,1,10\right.$, and $\left.100 \mu \mathrm{g} . \mathrm{mL}^{-1}\right)$ as well as its main bioactive molecule, caffeine, at proportional concentrations to those found in the extract. The results showed that guarana could serve as an important agent in antitumor pharmacologic therapies by inhibiting mTOR and MAPKs pathways. However, the most published studies are in vitro so it is necessary to explore novel ways to extrapolate the overwhelming beneficial evidence seen in pre-clinical studies to humans Table 1 .

Increasing evidence suggests that ingested food polyphenols can have beneficial effects in neuronal protection by acting against oxidative stress and inflammatory injury (Ashafaq et al., 2012; de Camargo et al., 2019; John and Shahidi, 2019; Wang et al., 2018; Zhang and Tsao, 2016; Zhang et al., 2018). Moreover, polyphenols 
Table 1. Studies in vitro or in vivo about health effects of guarana

\begin{tabular}{|c|c|c|c|}
\hline Health effects & In vitro/in vivo & Dose & References \\
\hline $\begin{array}{l}\text { Effects on metabolic comorbidities } \\
\text { (obesity, hypertension, type } 2 \\
\text { diabetes, and metabolic syndrome) }\end{array}$ & In vivo: elderly humans & Twice or more times a week & Krewer et al. (2011) \\
\hline $\begin{array}{l}\text { Oxidative stress and metabolic } \\
\text { disorders (effects on the } \\
\text { oxidation of LDL-c) }\end{array}$ & $\begin{array}{l}\text { In vivo: blood samples } \\
\text { of elderly humans; In } \\
\text { vitro: isolated LDL-c }\end{array}$ & $\begin{array}{l}\text { In vivo: at least } 5 \text { times per week In } \\
\text { vitro: } 0.05,0.1,0.5,1 \text {, and } 5 \mu \mathrm{g} \cdot \mathrm{mL}^{-1}\end{array}$ & Portella et al. (2013) \\
\hline Oxidative stress & $\begin{array}{l}\text { In vivo: overweight } \\
\text { humans; Ex vivo: oxidation } \\
\text { of LDL-c and total plasma } \\
\text { antioxidant capacity }\end{array}$ & $\begin{array}{l}\text { In vivo: } 3 \mathrm{~g} \text { of the powder diluted } \\
\text { in } 300 \mathrm{ml} \text { of water before intake, } \\
\text { daily for } 15 \text { days before breakfast }\end{array}$ & Yonekura et al. (2016) \\
\hline Antihyperglycemic & $\begin{array}{l}\text { In vitro: inhibition of activity } \\
\text { of carbohydrate-hydrolyzing } \\
\text { enzymes ( } \alpha \text {-amilase } \\
\text { and } \alpha \text {-glucosidase) }\end{array}$ & $\begin{array}{l}\text { Guarana extracts after in vitro } \\
\text { digestion } \alpha \text {-amilase: } 0.315 \text {, } \\
\left.0.525 \text { and } 0.875 \mathrm{mg} \cdot \mathrm{mL}^{-1}\right) ; \\
\alpha \text {-glucosidase: } 0.4 \text { and } 0.8 \mathrm{mg} \cdot \mathrm{mL}^{-1}\end{array}$ & Silva et al. (2018) \\
\hline $\begin{array}{l}\text { Gut microbial composition and redox } \\
\text { and inflammatory parameters }\end{array}$ & In vivo: Wistar rats & $\begin{array}{l}\text { Guarana seed powder the major } \\
\text { compounds are caffeine }(34.19 \\
\left. \pm 1.26 \mathrm{mg} \cdot \mathrm{g}^{-1}\right) \text {, theobromine } \\
\left(0.14 \pm 0.01 \mathrm{mg} \cdot \mathrm{g}^{-1}\right),(+) \text { - catechin } \\
\left(3.76 \pm 0.12 \mathrm{mg} \cdot \mathrm{g}^{-1}\right) \text {, and } \\
(-) \text {-epicatechin }\left(4.05 \pm 0.16 \mathrm{mg} \cdot \mathrm{g}^{-1}\right)\end{array}$ & Silveira et al. (2018) \\
\hline Antimicrobial activity & $\begin{array}{l}\text { In vitro: antibacterial potential } \\
\text { of the guarana extracts against } \\
\text { Streptococcus mutans }\end{array}$ & $\begin{array}{l}\text { The aqueous extract (AqE) from } \\
\text { the } 5 \%(w / v) \text { guarana seeds; } \\
\text { crude (EBPC) extracts and semi- } \\
\text { purified (EPA and EPB) fractions }\end{array}$ & $\begin{array}{l}\text { Yamaguti-Sasaki } \\
\text { et al. (2007) }\end{array}$ \\
\hline $\begin{array}{l}\text { Cognitive performance } \\
\text { and mental fatigue }\end{array}$ & In vivo: healthy young adults & $\begin{array}{l}\text { vitamin/mineral/guarana } \\
\text { combination }\end{array}$ & Kennedy et al. (2008) \\
\hline $\begin{array}{l}\text { Mood, cognitive performance } \\
\text { and functional brain activation }\end{array}$ & In vivo: healthy young adults & $\begin{array}{l}\text { vitamin/mineral/guarana } \\
\text { combination }\end{array}$ & Scholey et al. (2013) \\
\hline Antiproliferative effect & $\begin{array}{l}\text { In vitro: breast cancer } \\
\text { cells MCF-7 }\end{array}$ & $\begin{array}{l}\text { Guarana extracts } 1,5 \\
\text { and } 10 \mu \mathrm{g} \cdot \mathrm{mL}^{-1}\end{array}$ & Hertz et al. ( 2015) \\
\hline Anticancer effect & In vivo: female C57BI/6 mice & $2.0 \mathrm{mg} \cdot \mathrm{g}^{-1}$ body weight & Fukumasu et al. (2008) \\
\hline Antitumor effect & $\begin{array}{l}\text { In vitro: Colorectal and } \\
\text { breast cancer cell lineages } \\
\text { HT-29 and MCF-7 cells }\end{array}$ & $0.1,1,10$, and $100 \mu \mathrm{g} \cdot \mathrm{mL}^{-1}$ & Cadoná et al. (2017) \\
\hline
\end{tabular}

have been reported to promote cognitive functions (Filosa et al., 2018). A double-blind, randomised, placebo-controlled, parallel groups study assessed the acute effects of either a vitamin/mineral/guarana supplement or placebo drink in 129 healthy young adults (18-24 years). Participants completed a 10 min version of the Cognitive Demand Battery. Thirty minutes following their drink participants made six consecutive completions of the battery (i.e. $60 \mathrm{~min}$ ). The vitamin/mineral/guarana combination resulted in improved task performance, in comparison to placebo and the increase in mental fatigue associated with extended task performance was also attenuated by the supplement (Kennedy et al., 2008). Scholey et al. (2013) also confirmed the acute benefits of multivitamins with guarana on mood and cognitive performance.

It is, however, not fully understood which bioactive compound of guarana improves the mental health. Probably the effect of guarana is due to its caffeine content (Scholey et al., 2013). Adenosine seems to inhibit the release of many neurotransmitters in the central nervous system such as serotonin, noradrenaline and dopamine. Therefore, adenosine receptor antagonists, such as caffeine, promote the release of these various neurotransmitters (Mclellan et al., 2016; Kolahdouzan and Hamadeh, 2017). However, animal studies suggest that the powerful neuroprotective effects are due phenolic compounds content (chlorogenic acid, epigallocatechin gallate, curcumin, tannins). Their mode of action range from protection against oxidative stress to interaction with signaling pathways involved in maintaining energy homeostasis (Kennedy et al., 2008; Gomez-Pinilla and Nguyen, 2012).

Globally, depression is rising in an alarming manner, in almost every community of the world. The pathophysiology of depression is very complex, but the literature has shown the involvement of brain-derived neurotrophic factor (BDNF) as a crucial biomarker of this neural disorder. Some studies with phenolic compounds from blueberry and grape have shown that phenolic compounds are able to modulate important marker in brain tissue and could be an important factor to prevent brain diseases (Williams et al; 2008; Gomez-Pinilla and Nguyen, 2012; Dani et al., 2017). Therefore, further studies with guarana should investigate its role in modulation of BDNF.

In summary, this contribution shows that the potential health benefits of guarana go beyond the action of caffeine. Prevention of 
cardiovascular diseases and benefits on cognitive performance related to phenolics from guarana have been reported. Besides that, due to their inhibitory effect towards $\alpha$-glucosidase and $\alpha$-amylase, its promising action as a new antihyperglycemic agent for prevention and/or management of type 2 diabetes has been highlighted. Finally, as antibacterial ingredient, phenolic bioactives from guarana may counteract oral diseases (plaque and periodontal diseases). However, to confirm the benefits of guarana in humans, these evidences must be further addressed in clinical trials.

\section{References}

Abbas, M., Saeed, F., Anjum, F.M., Afzaal, M., Tufail, T., Bashir, M.S., and Suleria, H.A.R. (2017). Natural polyphenols: An overview. Int. J. Food Prop. 20: 1689-1699.

Amarowicz, R. (2016). Natural phenolic compounds protect LDL against oxidation. Eur. J. Lipid Sci. Tech. 118: 677-679.

Ashafaq, M., Raza, S.S., Khan, M.M., Ahmad, A., Javed, H., Ahmad, M.E., and Islam, F. (2012). Catechin hydrate ameliorates redox imbalance and limits inflammatory response in focal cerebral ischemia. Neurochem Res. 37: 1747-1760.

Agência Nacional de Vigilância Sanitária. (2019). Farmacopeia Brasileira 5a edição, Segundo Suplemento. http://portal.anvisa.gov.br/farmacopeias-virtuais. Accessed 17 Jun. 2019.

Agência Nacional de Vigilância Sanitária (ANVISA). (2019). Instrução Normativa no 28, de 26 de julho de 2018. Estabelece as listas de constituintes, de limites de uso, de alegações e de rotulagem complementar dos suplementos alimentares. Diário Oficial da União: seção 1, edição 144, p. 141. 27 jul 2018. http://www.in.gov.br/web/dou/-/ instrucao-normativa-in-n-28-de-26-de-julho-de-2018-34380550. Accessed 17 Jun. 2019.

Billingsley, H.E., and Carbone, S. (2018). The antioxidant potential of the Mediterranean diet in patients at high cardiovascular risk: an indepth review of the PREDIMED. Nutr. Diabetes. 8: 13.

Boeing, H., Bechthold, A., Bub, A., Ellinger, S., Haller, D., Kroke, A., and Stehle, P. (2012). Critical review: vegetables and fruit in the prevention of chronic diseases. Eur. J. Nutr. 51: 637-663.

Cadoná, F.C., Rosa, J.L., Schneider, T., Cubillos-Rojas, M., Sánchez-Tena, S., Azzolin, V.F., and da Cruz, I.B.M. (2017). Guaraná, a highly caffeinated food, presents in vitro antitumor activity in colorectal and breast cancer cell lines by inhibiting AKT/mTOR/S6K and MAPKs pathways. Nutr. Cancer 69: 800-810.

Canfora, E.E., Meex, R.C., Venema, K., and Blaak, E.E. (2019). Gut microbial metabolites in obesity, NAFLD and T2DM. Nat. Rev. Endocrinol. 15: 261-273.

Chiu, H.-F., Shen, Y.-C., Venkatakrishnan, K., and Wang, C.-K. (2018). Popular functional foods and nutraceuticals with lipid lowering activity and in relation to cardiovascular disease, dyslipidemia, and related complications: an overview. J. Food Bioact. 2: 16-27.

Cilla, A., Bosch, L., Barberá, R., and Alegría, A. (2018). Effect of processing on the bioaccessibility of bioactive compounds-a review focusing on carotenoids, minerals, ascorbic acid, tocopherols and polyphenols. J. Food Compos. Anal. 68: 3-15.

Cires, M.J., Wong, X., Carrasco-Pozo, C., and Gotteland, M. (2017). The gastrointestinal tract as a key target organ for the health-promoting effects of dietary proanthocyanidins. Front. Nutr. 3: 57.

de Camargo, A.C., Biasoto, A.C.T., Schwember, A.R., Granato, D., Rasera, G.B., Franchin, M., and Shahidi, F. (2019). Should we ban total phenolics and antioxidant screening methods? The link between antioxidant potential and activation of NF-KB using phenolic compounds from grape by-products. Food Chem. 290: 229-238.

de Camargo, A.C., Regitano-d'Arce, M.A.B., Rasera, G.B., Canniatti-Brazaca, S.G., do Prado Silva, L., Alvarenga, V.O., and Shahidi, F. (2017). Phenolic acids and flavonoids of peanut by-products: Antioxidant capacity and antimicrobial effects. Food Chem. 237: 538-544.

Dani, C., Andreazza, A.C., Goncalves, C.A., Kapizinski, F., Henriques, J.A., and Salvador, M. (2017). Grape juice increases the BDNF levels but not alter the $\mathrm{S} 100 \mathrm{~B}$ levels in hippocampus and frontal cortex from male Wistar Rats. An. Acad. Bras. Cienc. 89: 155-161.

de Camargo, A.C., Schwember, A.R., Parada, R., Garcia, S., Maróstica, M.R., Franchin, M., and Shahidi, F. (2018). Opinion on the hurdles and potential health benefits in value-added use of plant food processing byproducts as sources of phenolic compounds. Int. J. Mol. Sci. 9: 3498.

Filosa, S., Di Meo, F., and Crispi, S. (2018). Polyphenols-gut microbiota interplay and brain neuromodulation. Neural. Regen. Res. 13: 2055.

Fukumasu, H., Avanzo, J.L., Nagamine, M.K., Barbuto, J.A., Rao, K.V., and Dagli, M.L.Z. (2008). Paullinia cupana Mart var. sorbilis, guaraná, reduces cell proliferation and increases apoptosis of B16/F10 melanoma lung metastases in mice. Braz J. Med. Biol. Res. 41: 305-310.

Gomez-Pinilla, F., and Nguyen, T.T. (2012). Natural mood foods: the actions of polyphenols against psychiatric and cognitive disorders. Nutr. Neurosci. 15: 127-133.

Hanhineva, K., Törrönen, R., Bondia-Pons, I., Pekkinen, J., Kolehmainen, M., Mykkänen, H., and Poutanen, K. (2010). Impact of dietary polyphenols on carbohydrate metabolism. Int. J. Mol. Sci. 11: 1365-1402.

Hertz, E., Cadoná, F.C., Machado, A.K., Azzolin, V., Holmrich, S., Assmann, C., and da Cruz, I.B.M. (2015). Effect of Paullinia cupana on MCF-7 breast cancer cell response to chemotherapeutic drugs. Mol. Clin. Oncol. 3: 37-43.

John, J.A., and Shahidi, F. (2019). Phenolic content, antioxidant and antiinflammatory activities of seeds and leaves of date palm (Phoenix dactylifera L.). J. Food Bioact. 5: 120-130.

Karasawa, M.M.G., and Mohan, C. (2018). Fruits as prospective reserves of bioactive compounds: a review. Nat. Prod. Bioprospect. 8: 335-346.

Kennedy, D.O., Haskell, C.F., Robertson, B., Reay, J., Brewster-Maund, C., Luedemann, J., and Scholey, A.B. (2008). Improved cognitive performance and mental fatigue following a multi-vitamin and mineral supplement with added guarana (Paulinia cupana). Appetite 50: 506-513.

Kim, Y., Keogh, J.B., and Clifton, P.M. (2016). Polyphenols and glycemic control. Nutrients 8: 17.

Kolahdouzan, M., and Hamadeh, M.J. (2017). The neuroprotective effects of caffeine in neurodegenerative diseases. CNS Neurosci. Ther. 23: 272-290.

Krewer, C.C., Ribeiro, E.E., Ribeiro, E.A.M., Moresco, R.N., de Ugalde Marques da Rocha, M.I., dos Santos Montagner, G.F.F., and da Cruz, I.B.M. (2011). Habitual intake of guaraná and metabolic morbidities: an epidemiological study of an elderly Amazonian population. Phytother. Res. 25: 1367-1374.

Majhenič, L., Škerget, M., and Knez, ž. (2007). Antioxidant and antimicrobial activity of guarana seed extracts. Food Chem. 104: 1258-1268.

McLellan, T.M., Caldwell, J.A., and Lieberman, H.R. (2016). A review of caffeine's effects on cognitive, physical and occupational performance. Neurosci. Biobehav. Rev. 71: 294-312.

Mendes, T.M.N., Murayama, Y., Yamaguchi, N., Sampaio, G.R., Fontes, L.C.B., da Silva Torres, E.A.F., and Yonekura, L. (2019). Guaraná (Paullinia cupana) catechins and procyanidins: Gastrointestinal/colonic bioaccessibility, Caco-2 cell permeability and the impact of macronutrients. J. Funct. Foods 55: 352-361.

Ozdal, T., Sela, D.A., Xiao, J., Boyacioglu, D., Chen, F., and Capanoglu, E. (2016). The reciprocal interactions between polyphenols and gut microbiota and effects on bioaccessibility. Nutrients 8: 78.

Portella, R.L., Barcelos, R.P., da Rosa, E.J.F., Ribeiro, E.E., da Cruz, I.B.M. Suleiman, L., and Soares, F.A.A. (2013). Guaraná (Paullinia cupana Kunth) effects on LDL oxidation in elderly people: an in vitro and in vivo study. Lipids Health Dis. 12: 12.

Santana, Á.L., and Macedo, G.A. (2018). Health and technological aspects of methylxanthines and polyphenols from guarana: A review. J. Funct. Foods 47: 457-468.

Schimpl, F.C., da Silva, J.F., de Carvalho Gonçalves, J.F., and Mazzafera, P. (2013). Guarana: Revisiting a highly caffeinated plant from the Amazon. J. Ethnopharmacol. 150: 14-31.

Scholey, A., Bauer, I., Neale, C., Savage, K., Camfield, D., White, D., and Hughes, M. (2013). Acute effects of different multivitamin mineral preparations with and without guaraná on mood, cognitive performance and functional brain activation. Nutrients 5: 3589-3604.

Shahidi, F., and Peng, H. (2018). Bioaccessibility and bioavailability of phenolic compounds. J. Food Bioact. 4: 11-68.

Shahidi, F., Varatharajan, V., Oh, W.Y., and Peng, H. (2019). Phenolic com- 
pounds in agri-food by-products, their bioavailability and health effects. J. Food Bioact. 5: 57-119.

Silva, C.P., Sampaio, G.R., Freitas, R.A.M.S., and Torres, E.A.F.S. (2018). Polyphenols from guaraná after in vitro digestion: Evaluation of bioacessibility and inhibition of activity of carbohydrate-hydrolyzing enzymes. Food Chem. 267: 405-409.

Silveira, A.K., Moresco, K.S., Mautone Gomes, H., da Silva Morrone, M., Kich Grun, L., Pens Gelain, D., and Fonseca Moreira, J.C. (2018). Guarana (Paullinia cupana Mart.) alters gut microbiota and modulates redox status, partially via caffeine in Wistar rats. Phytother Res. 32: $2466-2474$.

Vauzour, D., Rodriguez-Mateos, A., Corona, G., Oruna-Concha, M.J., and Spencer, J.P. (2010). Polyphenols and human health: prevention of disease and mechanisms of action. Nutrients 2: 1106-1131.

Williams, C.M., El Mohsen, M.A., Vauzour, D., Rendeiro, C., Butler, L.T., Ellis, J.A., and Spencer, J.P. (2008). Blueberry-induced changes in spatial working memory correlate with changes in hippocampal CREB phosphorylation and brain-derived neurotrophic factor (BDNF) levels. Free Radic. Biol. Med. 45: 295-305.

World Health Organization. (2018). Noncommunicable diseases country profiles 2018. https://www.who.int/nmh/publications/ncd-profiles-2018/en/ Accessed 18 Jun. 2019.

Wang, X., Li, S., Wei, C.-C., Huang, J., Pan, M.-H., Shahidi, F., and Ho, C.-T. (2018). Anti-inflammatory effects of polymethoxyflavones from citrus peels: a review. J. Food Bioact. 3: 76-86.

Yamaguti-Sasaki, E., Ito, L., Canteli, V., Ushirobira, T., Ueda-Nakamura, T., Nakamura, C., and Palazzo de Mello, J. (2007). Antioxidant capacity and in vitro prevention of dental plaque formation by extracts and condensed tannins of Paullinia cupana. Molecules 12: 1950-1963.

Yonekura, L., Martins, C.A., Sampaio, G.R., Monteiro, M.P., César, L.A.M., Mioto, B.M., and da Silva Torres, E.A.F. (2016). Bioavailability of catechins from guaraná (Paullinia cupana) and its effect on antioxidant enzymes and other oxidative stress markers in healthy human subjects. Food Funct. 7: 2970-2978.

Zhang, B., Peng, H., Deng, Z., and Tsao, R. (2018). Phytochemicals of lentil (Lens culinaris) and their antioxidant and anti-inflammatory effects. J. Food Bioact. 1: 93-103.

Zhang, H., and Tsao, R. (2016). Dietary polyphenols, oxidative stress and antioxidant and anti-inflammatory effects. Curr. Opin. Food Sci. 8: 33-42. 